\title{
Reflexões iniciais sobre a identidade tipográfica brasileira
}

\author{
First reflections on the Brazilian typographic identity \\ Eduardo H.C. Azerêdo, Isabella Ribeiro Aragão
}

design brasileiro, identidade nacional, tipografia, design de tipos.

A tentativa de caracterização da identidade brasileira no design de tipos requer um estudo dos conceitos de design, identidade e tipografia que incorporam a questão. Este artigo levanta questionamentos sobre o tema a partir de uma pesquisa bibliográfica, apresentando resultados que consideram o papel cultural, econômico e social do design. Com o estabelecimento dos conceitos, é avaliada a trajetória do design brasileiro de um ponto de vista da tipografia, o que revela um entendimento de diferentes situações em que a identidade nacional pode manifestar-se, seja nos tipos de metal ou na tipografia digital.

brazillian design, national identity, typography, type design

The attempt to characterize the Brazilian identity in type design requires a study of the concepts of design, identity and typography that incorporate the issue. This article raises questions about the theme from a bibliographic research, presenting results that consider the cultural, economic and social role of design. With the establishment of the concepts, the trajectory of Brazilian design is evaluated from a typographic point of view, which reveals an understanding of different situations in which the national identity can manifest itself, whether in the types of metal or in digital typography.

\section{Introdução}

A ideia de um design brasileiro aponta para diversos pontos de partida da atividade no país, sendo o principal deles a institucionalização da atividade através da fundação da EsDI, em 1962. Anteriormente, contudo, já existiam atividades industriais nos campos do design gráfico e tipográfico, o que fomenta indagações a respeito do que se considera design no contexto brasileiro e de como essas atividades se relacionavam com a identidade nacional.

Este artigo visa entender as relações entre a produção tipográfica brasileira nas eras de metal e digital a partir de uma abordagem social, cultural e histórica. Para isso, foi realizada uma pesquisa bibliográfica baseada em autores que versam sobre design gráfico, identidade nacional, tipos de metal, fontes digitais e tipografia vernacular, em especial, Villas-Boas (2009) e Fukushiro (2014). Com isso, pretendemos estabelecer reflexões iniciais que auxiliam no entendimento da identidade do design brasileiro por um ponto de vista da tipografia. Curitiba | Brazil | 2021 


\section{Design e Identidade Nacional}

Em suas investigações sobre o percurso tomado pelo design no país, Niemeyer (1998) utilizase justamente da década de 60 e da institucionalização citada acima como pontos de partida para suas análises. Cardoso (2005), contudo, alega que a produção industrial brasileira precedente é suficiente para confirmar a existência de atividade projetual em território nacional considerando-a essencial para "uma melhor compreensão daquilo que pode ser entendido como uma identidade brasileira no campo do design" (Cardoso, 2005, p.12).

Essa divergência entre os autores é consequência de um diferente entendimento do conceito de design. Cardoso (2005) define design enquanto uma atividade projetual imbricada à serialização, sendo essa a condição necessária para sua existência.

Além desses aspectos, Villas-Boas (2009) apresenta uma conceituação cultural do design gráfico definindo-o como "um discurso, e como tal espelha a condição cultural na qual e para a qual foi concebido ao mesmo tempo em que contribui para produzir, realimentar ou transformar esta mesma condição cultural" (Villas-Boas, 2009, p.21).

Como base para compreender as relações entre design e identidade nacional, o autor apresenta o conceito de autonomia projetual, isto é,

o conceito de que o projeto nasce da autonomia do designer no exame e na elaboração da solução para a situação de projeto - que é construída visceralmente dependente da própria situação de projeto, porque autônoma de qualquer outra instância (a tradição estrangeira, o apriorístico de dados materiais e linguagens, os preconceitos estilísticos, os parâmetros de outros campos, etc). (Villas- Boas, 2009, p.84)

A partir dessa definição, é impensável delinear a identidade do design brasileiro baseandose em experiências consolidadas em campos adjacentes, como a arquitetura. É preciso, então, que o design formule soluções originais, não optando pela inserção de símbolos e práticas previamente admitidas como símbolos de brasilidade. De que forma a brasilidade tem se manifestado na produção tipográfica desde os tipos de chumbo?

\section{Tipografia e brasilidade}

De modo similar à teoria de autonomia projetual defendida por Villas-Boas (2009) mas já com um enfoque no campo tipográfico, Fukushiro (2014) avalia que elementos com valores préestabelecidos de brasilidade, ao serem incorporados propositalmente a uma produção de design, não resultam na formação de uma identidade própria.

Fundamentando-se em pensamentos de Mário de Andrade, Fukushiro (2014) atribui um caráter de inconsciência à construção dessa identidade do design brasileiro, sendo essa uma condição para seu desenvolvimento. Dessa forma, um dos caminhos possíveis para tentar compreender a identidade tipográfica nacional é atentar para fatores que se enquadrem nos conceitos de inconsciência e autonomia projetual descritos por Fukushiro (2014) e Villas-Boas (2009). Esses aspectos podem ser discutidos tanto na época dos tipos de metal quanto na era digital, como exposto a seguir. 


\section{Tipos de metal}

Devido a sua condição de colônia e à proibição do uso de prensas tipográficas em território nacional, o primeiro contato oficial do Brasil com a tecnologia dos tipos móveis deu-se tardiamente em 1808 com a vinda da corte portuguesa para o Rio de Janeiro. Vale salientar ainda que a fundição de tipos - e, consequentemente, a possibilidade de criação de desenhos originais - iniciou-se alguns anos mais tarde.

Apesar das investigações de Lima (2005) não evidenciarem fabricação de tipos nacionais em território brasileiro no século XIX, sendo a fundição de tipos no período uma atividade de características quase artesanais, o estudo de Martins, Lima e Lima (2017) apresenta um curioso caso ocorrido no Norte do país em que João Francisco Madureira, em 1821, afirma ter desenvolvido todo o processo tipográfico sem treino ou conhecimento prático. Os pesquisadores concluem que um tipo com características irregulares de um requerimento impresso pelo paraense comprova sua afirmação. Portanto, uma observação mais detalhada nos caracteres pode apontar a originalidade de seu desenho.

Em investigação sobre a maior fundição brasileira do século XX - a Funtimod -, que já possuía um caráter industrial, Aragão (2016) constatou que suas faces eram fabricadas a partir de matrizes importadas do exterior, sobretudo da Alemanha. Ao comparar nove catálogos de tipos da Funtimod, Aragão (2016) evidenciou alterações entre alguns caracteres, sobretudo nos diacríticos. Sabe-se que à época, as fundições de tipos as quais a Funtimod mantinha relações comerciais - como a D. Stempel - tinham a prática de comercializar matrizes adequadas a diferentes idiomas, o que requer a concepção dos glifos em questão. (Aragão, 2016)

Contudo, diante de uma análise detalhada das alterações entre os catálogos com auxílio de microscópio, a autora (Aragão, 2016) afirma que uma parte dos achados, principalmente os diacríticos dos caracteres "ã" e "ç", são resultado de uma fabricação manual ocorrida em solo brasileiro. Dessa forma, apesar de não poderem ser consideradas brasileiras, as faces apresentam caracteres com traços que refletem uma prática com características nacionais, com algumas soluções originais, e contribuem para a cultura tipográfica do país.

\section{Tipos digitais}

O advento do computador na década de 80 proporcionou ao design gráfico uma gama de ferramentas que permitiram um caráter mais experimental. No que se refere ao design de tipos, essa transformação traduziu-se em um distanciamento entre os projetos e os rígidos dogmas modernistas. (Cauduro, 2002)

Contudo, devido ao atraso tecnológico do país, não foi evidenciada uma grande produção de design de tipos. A primeira fonte digital do Brasil surgiu apenas em 1989, lançada por Tony de Marco, e, nas décadas seguintes, as criações nacionais resumiram-se a fontes display de caráter pós-modernista. (Gomes, 2010)

Essa tendência pode ser encarada, de acordo com Cauduro (2002), como uma reinserção da subjetividade do designer na sua produção. Consoante o autor, 
Nesse movimento de regresso às raízes artísticas do design, de desmistificação do seu caráter pseudo-científico, de revalorização da retórica e da emotividade sobre a lógica fria, observamos que a intuição e a imperfeição são muito valorizadas, porque tendem a ser marcas únicas de cada sujeito e de cada contexto social no momento histórico específico de resolução de problemas comunicacionais. (Cauduro, 2002, p.7).

Diante disso, é possível afirmar que o cenário brasileiro a partir da década de 90 era propício à consolidação de uma identidade tipográfica local. Para Gomes (2010), houve uma tentativa de caracterizar o design tipográfico brasileiro na época pois, além do destaque constatado pela tipografia no contexto nacional - a partir de revistas e exposições que promoveram a valorização da classe -, foram evidentes as experimentações que buscavam incorporar o letreiramento popular à tipografia digital.

Podendo ser entendido como uma tradição cultural transmitida de maneira informal (Finizola, 2010), o design vernacular, através do letreiramento popular, mostrou-se desde a década de 90 como uma alternativa à falta de tradição tipográfica brasileira. Gomes (2010) critica essa valorização do vernacular ao indagar sobre as consequências do uso de desenhos "toscos" ou pouco "lapidados" como base para criação da identidade tipográfica nacional. Fukushiro (2014), por sua vez, questiona a apropriação dos desenhos e consequente perda do significado de resistência intrínseco ao letreiramento popular.

O Brasil só experienciou um maior desenvolvimento da área nos anos 2000. Segundo Gomes (2010), o avanço da globalização levou os profissionais brasileiros a estudarem e atuarem no exterior, o que posteriormente contribuiu para a consolidação do campo internamente. Nesse período, o desenvolvimento do mercado editorial também abriu novas oportunidades para o campo tipográfico, como na criação da família Houaiss em 2001 para o dicionário homônimo, principalmente por tratar-se de uma fonte de texto em contraposição à predominância de tipos display na produção brasileira (Gomes, 2010).

\section{Considerações Finais}

Considerando que a construção da identidade do design brasileiro está condicionada à autonomia e à inconsciência e que, sendo a tipografia um dos elementos primordiais dos projetos de design da informação, torna-se necessário um contexto local de produção para que se construa uma identidade tipográfica.

Somente a partir desse contexto produtivo pode ser observada a manifestação de elementos provenientes da inconsciência do povo e de soluções projetuais originalmente brasileiras na tipografia, apresentando-se através de especificidades históricas e culturais nacionais que vão desde tipos móveis até os digitais. A produção de tipos do Brasil iniciou com as adaptações em caracteres específicos de tipos de metal, passou por uma fase experimental de tipos digitais das décadas de 1980-1990 até chegar em uma vasta produção de tipos de texto e tipos display da atualidade. 


\section{Referências}

Aragão, Isabella R. (2016). Tipos móveis de metal da Funtimod: contribuições para a história tipográfica brasileira. 2016. Tese (Doutorado em Design e Arquitetura) - Faculdade de Arquitetura e Urbanismo, Universidade de São Paulo, São Paulo.

Cardoso, Rafael. (org). (2005). O design brasileiro antes do design: aspectos da história gráfica, 1870-1960. São Paulo: Cosac Naify.

Cauduro, Flávio V. (2002). O imaginário tipográfico pós-moderno. In: XI Compós, 2002, Rio de Janeiro. CD-ROM XI COMPÓS, 2002. v. 1. p. 1-1.

Finizola, Fátima. (2010). Panorama tipográfico dos letreiramentos populares: um estudo de caso na cidade do Recife. 2010. Dissertação (Mestrado). Programa de Pós-Graduação em Design, Universidade Federal de Pernambuco, Recife.

Fukushiro, Luiz. (2015). Ensaio sobre a tipografia brasileira. Pós. Revista do Programa de PósGraduação em Arquitetura e Urbanismo da FAUUSP, [S. I.], v. 21, n. 36, p. 194-208.

Gomes, Ricardo E. (2010). O design brasileiro de tipos digitais: elementos que se articulam na formação de uma prática profissional. Dissertação (Mestrado em Design) - Escola Superior de Desenho Industrial, Universidade do Estado do Rio de Janeiro, Rio de Janeiro.

Lima, Edna L.C. (2005). Fundidoras de Tipo do Século XIX Anunciantes no Almanack Laemmert. Relatório de Pesquisa da Biblioteca Nacional do Rio de Janeiro. Rio de Janeiro.

Martins, Fernanda de O.; Lima, Edna C.; Lima, Guilherme C. O engenhoso pioneiro da tipografia da Província do Grão-Pará - João Francisco Madureira, p. 1196-1207. In: Blucher Design Proceedings. São Paulo: Blucher, 2018.

Niemeyer, Lucy. (1998). Design no Brasil: origens e instalação. Rio de Janeiro: 2AB.

Villas-Boas, André. (2009). Identidade e Cultura: design gráfico. $2^{\mathrm{a}}$ edição. Teresópolis: 2AB.

\section{Sobre os autores}

Eduardo Henrique Calheiros Azerêdo, graduando, UFPE, Brasil <ehcazeredo@gmail.com> Isabella Ribeiro Aragão, Dra., UFPE, Brasil <isabella.aragao@ufpe.br> 